\title{
Reverse total shoulder versus angular stable plate treatment for proximal humeral fractures in over 65 years old patients
}

\author{
Antonio Giardella ${ }^{1}$ \\ Francesco Ascione ${ }^{1}$ \\ Mattia Mocchi ${ }^{2}$ \\ Marco Berlusconi² \\ Alfonso Maria Romano ${ }^{1}$ \\ Francesco Oliva ${ }^{3}$ \\ Leonardo Maradei ${ }^{1}$
}

Istituto Clinico Humanitas, IRCCS, Rozzano, Milan, Italy

1 Unità Operativa di Chirurgia Mini-Invasiva

2 Unità Operativa di Traumatologia II

3 Department of Orthopaedics and Traumatology, University of Rome "Tor Vergata", Italy

Corresponding author:

Antonio Giardella

Unità Operativa di Chirurgia Mini-Invasiva

Department of Orthopaedic and Traumatology,

Istituto Clinico Humanitas, IRCCS

Rozzano (MI), Italy

E-mail: info@antoniogiardella.com

\section{Summary}

Background: Treatment for displaced proximal humeral fractures is still under debate. Poor rotator cuff status and non-union of the tubercles in elderly patients has caused reversed total shoulder prosthesis growing popularity and showed promising results, even in comparison to angular stable plates fixation.

The purpose of this study is to report clinical and radiological results of proximal humerus fractures treated with rTSA or ORIF in elderly.

Materials and methods: The study has investigated retrospectively a consecutive series of 73 patients over 65 years old (range 65-91) with proximal humeral three- and four- parts fractures, operated from January 2009 to June 2014 with a reversed total shoulder prosthetic replacement or open reduction and internal fixation using an angular stable plate, with at least 1 year follow-up. Participants are admitted in our hospital with a displaced proximal humeral fracture according to
AO-OTA type 11-B2 or 11-C2.

The primary outcomes are active ROM and shoulder function (Constant score). Secondary outcomes have been patient self-assessment form (Simple shoulder test) and radiographical details. Follow-up takes place at the moment of clinical observation with rx control.

Results: We analyzed a group of 23 patients treated by plate and screws and 21 patients treated by rTSA with these average results. ORIF: Flexion $112.8^{\circ}$, Abduction $99.6^{\circ}$, External rotation at $90^{\circ}$ $47.4^{\circ}$, modal Internal rotation hand at Sacroiliac joint, Constant Score $\mathbf{5 2 . 9}$ and Simple Shoulder Test 8.0. RSA: Flexion $133.3^{\circ}$, Abduction $101.4^{\circ}$, External rotation at $90^{\circ}$ of abduction $35.5^{\circ}$, modal Internal rotation hand at waist (L3), Constant Score 65.9 and Simple Shoulder Test 9.2. No nerve injuries were reported. No cases of pseudoarthrosis or plate fractures. No arthroplasty implant loosening, infection or dislocation was documented and revision required.

Conclusion: Our study shows good clinical outcomes and fewer complications in both treatment options. Better clinical and daily living results are reported in RSA compared with ORIF, confirming that rTSA is one of the best treatment in proximal humeral fractures in the elderly patients, which rotator cuff status frequently is poor and degenerating. The few radiological complications do not seem to have influence on active ROM and Constant Score, both the first and the second group of patients.

Level of evidence: Level IV, Case Series, Surgical.

KEY WORDS: fractures proximal humerus, surgical treatment, replacement, clinical and radiological outcomes, reverse total shoulder arthroplasty, angular stable plate, shoulder, elderly.

\section{Introduction}

Humeral proximal fractures represent $6-8 \%$ of all fractures and most of them are low-energy osteoporotic injuries in the elderly patients with an increasing incidence $^{1}$. Treatment for displaced proximal humeral fractures is still under debate with a constantly expanding range of options, several decades after the first recommendations for "modern treatment princi- 
ples" given by Neer ${ }^{1,2}$. This remains the most commonly used classification, but additional systems have been described more recently, giving other useful indications to surgeon for type of surgery to adopt. Most patients sustaining these fractures are women above the age of 60 . The incidence of the proximal humeral fracture has been reported to increase with age during several decades, also according to incidence of falls and osteoporosis as the main risk factors $^{3,4}$.

Humeral fractures in the elderly represent in general a considerable burden to the patients in terms of pain, loss of function and even mortality, making selfcare and independent living difficult, thus interfering with quality of life 5,6 .

In last years, in period from 1999 to 2005, there is evidence that surgical treatment has increased significantly ${ }^{7}$ : concerning three- and four- part fractures, many surgeons decide for operative treatment, even if there is not scientific evidence that conservative approach is superior to surgery in displaced fractures 8,9 .

If surgery is decided, the most frequent treatment modalities are open reduction and internal fixation with an angular stable plate, a locked intramedullary nail, minimally open surgery with screws and cerclage wires or shoulder arthroplasty, total or hemi, widely used ${ }^{10-11}$, or in the last few years with a reverse shoulder implant ${ }^{12-14}$.

The purpose of this retrospective study was to compare and analyze clinical and radiological outcomes of three- and four- part proximal humeral fractures in two groups of patients older than 65 years, the first treated with ORIF, the second with RSA.

\section{Materials and methods}

From January 2009 to October 2014, in our Hospital a consecutive series of 73 patients over 65 years old underwent to surgery after a three- or four- part proximal humeral fracture. The fracture was classified by X-rays according to trauma series and CT scan in all patients. We excluded from the study 4 patients with an associated fracture (1 radius fracture, 3 femur fractures), 3 longstanding fractures operated more than 7 days after trauma, 2 radial nerve injuries, 7 patients died and 13 patients didn't accept the clinical and radiological follow-up or were too old to come in hospital. Among the patients enrolled in the study, anyone had acute or chronic damage of the axillary nerve. We have followed 44 patients with a minimum follow-up of 12 months, analyzing functional, clinical and radiological outcomes by active range of motion, Constant's score, Simple shoulder test and shoulder X-Ray by a true AP view and an axillary view. Three independent observers checked $x$-rays images (FA, $A G, M M)$ and one (FA) performed clinical follow up evaluation.
Patients were divided in two groups: one group operated with ORIF by angle-stable plate PHILOS (PHLPSYNTHES, Oberdorf, Switzerland) and one group with a reverse total shoulder arthroplasty SMR (LIMA Corporate, San Benedetto del Friuli, Italy).

All surgeries were performed within the first week from the injury. The choice of replacement or ORIF was due to shoulder clinical history before the trauma and CT cuff status, given and performed by two senior surgeons (LM, MB). A lateral approach was used in patients treated with plate and screws, to obtain a better synthesis of posterior fragments and good reduction of tuberosities with non-absorbable wires. We practiced a deltopectoral approach in patients treated by RSA because we found it comfortable to implant glenoid baseplate, control its inclination, eliminate axillary nerve injuries risk and above all, it doesn't require deltoid detachment and attempt RSA success; in RSA we never cemented prosthesis and used a 40 or $44 \mathrm{~mm}$ glenosphere and humerus placed in $20^{\circ}$ of retroversion. Greater tuberosity was repaired in every intervention and subscapularis tendon was sutured with no. 2 non-absorbable wires in 13 RSA and 8 was impossible to close.

Rehabilitation was different for the groups: patients treated by ORIF were placed in a sling for 3 weeks, therapy is initiated on postoperative day 1 with gentle, gravity-assisted pendulum exercises and avoided rotation for 7 weeks, active assisted rom exercises after 40th day Rx control; after $7^{\text {th }}$ week patients began active rom exercises and rotation strengthening. RSA intervention patients wore shoulder immobilizer with 15 degrees of abduction for 4 weeks, therapy initiated on postoperative day 1 with gentle, gravity-assisted pendulum exercises and avoided external rotation for 6 weeks; passive rom exercises for 4 weeks from the $2^{\text {nd }}$ and active assisted and active rom exercises for 6 weeks until independent home exercises. All data were described as number and percentage, or mean and standard deviation, or median and range where appropriated. Difference between group were explored with fisher exact test, or Wilcoxon test, where appropriated.

All analysis were made with the program Stata 13. A p less than 0.05 was considered as significant.

\section{Results}

In our series of 44 elderly patients, at a minimum follow-up of 12 months, all patients were satisfied with their shoulder, except one in RSA intervention (CS 40) and every patient had a good or excellent pain control. The patients' average age was 73.2 years, with range 65-91 years. Patients were divided in 23 [16 $(69.9 \%)$ women] operated with ORIF by anglestable plate PHILOS (PHLP-SYNTHES, Oberdorf, Switzerland) and 21 [18 (85.7\%) women] with a reverse total shoulder arthroplasty SMR (LIMA Corpo- 
rate, San Benedetto del Friuli, Italy). The mean age of surgery was $77.2 \pm 6.4$ years for RSA and $72.1 \pm$ 6.0 years for ORIF; the median number of months of follow-up was $28(12-84)$ totally, respectively 24 (1284) months for RSA and 40 (12-66) months for ORIF. In both groups was reported an improved degree of movements and an improvement of the clinical and functional conditions. External rotation with the arm at $90^{\circ}$ of abduction is preferentially reported because it is the requested one in daily living activities. We found a statistically significant difference between the two groups analyzing forward flexion and Constant score value, respectively p 0.008 and 0.013 , and external rotation with $90^{\circ}$ of abduction, p 0.05 .

The results are summarized in Table I.

The ORIF group average values were: Flexion $112.8^{\circ}$, Abduction $99.6^{\circ}$, External rotation at $90^{\circ}$ $47.4^{\circ}$, modal Internal rotation hand at Sacroiliac joint, Constant Score 52.9 and Simple Shoulder Test 8.0.

Concerning the RSA group, mean Flexion was $133.3^{\circ}$, Abduction $101.4^{\circ}$, External rotation at $90^{\circ}$ of abduction $35.5^{\circ}$, modal Internal rotation hand at waist (L3), Constant Score 65.9 and Simple Shoulder Test 9.2.

Comparing the two groups, differences in: no axillary nerve injuries were reported; no cases of pseudoarthrosis or plate fracture; no arthroplasty implant loosening, infection or dislocation was documented and revision required.

\section{Radiological outcomes}

All patients were evaluated with a true AP view and a scapular $Y$ view at the moment of follow-up, considering different parameters for the group.

For ORIF group, no plates resulted with one screw cut-out (Fig. 1), 2 shoulders had a partial reabsorption of greater tuberosity (Fig. 2) and 1 of the lesser, 1 humeral heads went to partial necrosis.

Regarding RSA group, inferior scapular notching according to Nerot classification ${ }^{15}, 16$ was considered: notching observed as grade 0 in 19 shoulders and

Table I. Results.

\begin{tabular}{llll}
\hline & ORIF & RSA & p \\
\hline N. of patients & 23 & 21 & 0.008 \\
Flexion & $112.8 \pm 21.0$ & $133.3 \pm 32.6$ & 0.659 \\
Abduction & $99.6 \pm 17.4$ & $101.4 \pm 19.0$ & 0.050 \\
External rotation $\left(90^{\circ}\right.$ abduction) & $47.4 \pm 20.2$ & $35.5 \pm 15.6$ & Waist (L3) \\
Internal rotation & Saroiliac joint & $7(33.3 \%)$ & 0.013 \\
& $9(39.1 \%)$ & $65.9 \pm 14.7$ & 0.053 \\
CS & $52.9 \pm 17.0$ & $9.2 \pm 2.0$ & \\
\hline
\end{tabular}

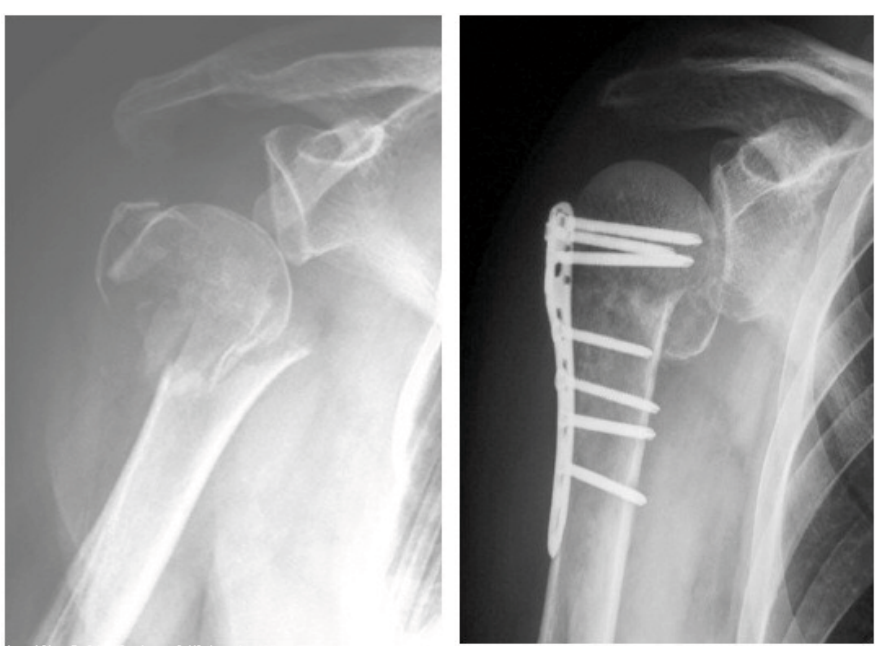

Figure 1. Fracture type $\mathrm{C}$ treated with ORIF. 

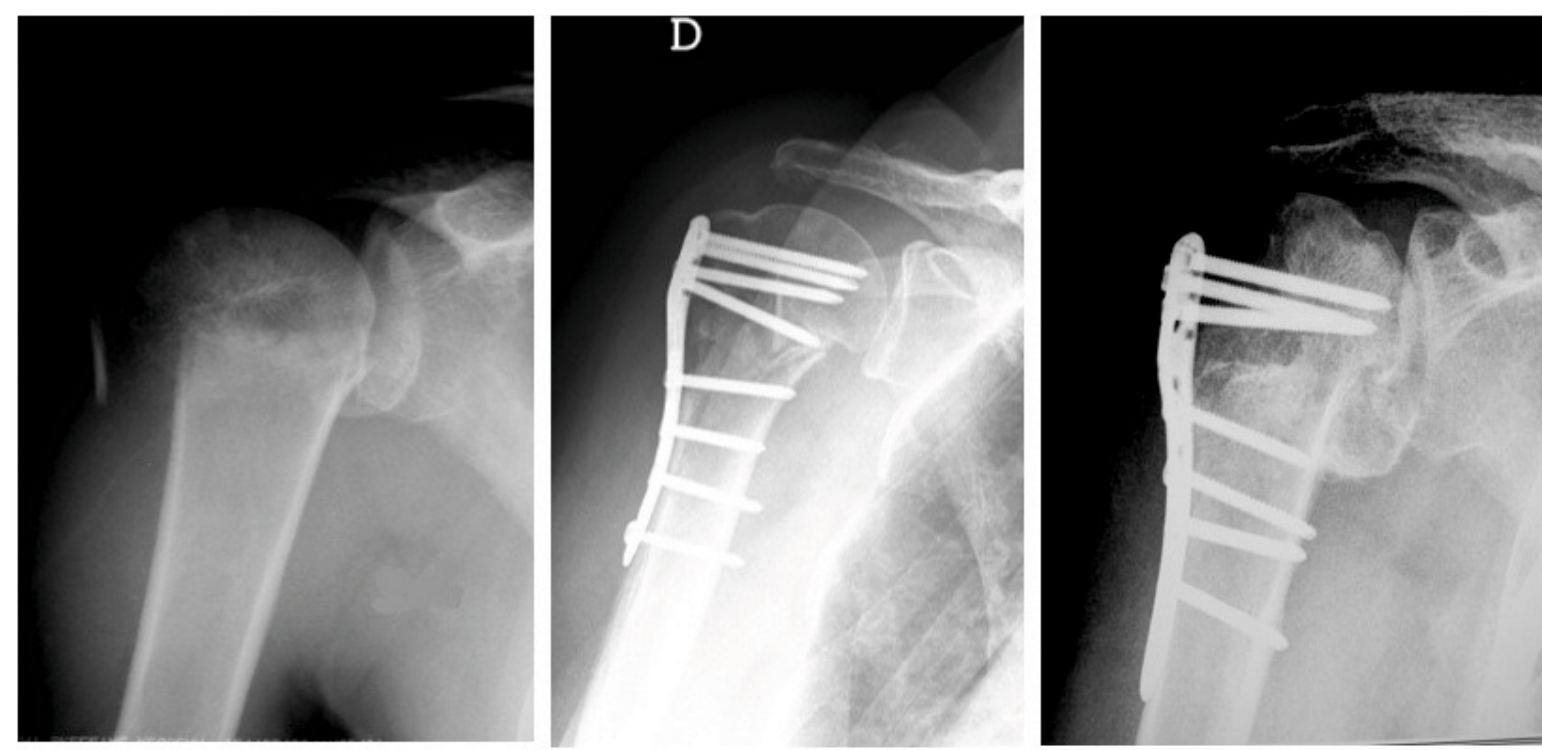

Figure 2. Fracture type $\mathrm{C}$ treated with ORIF with a partial re-absorption of greater tuberosity.
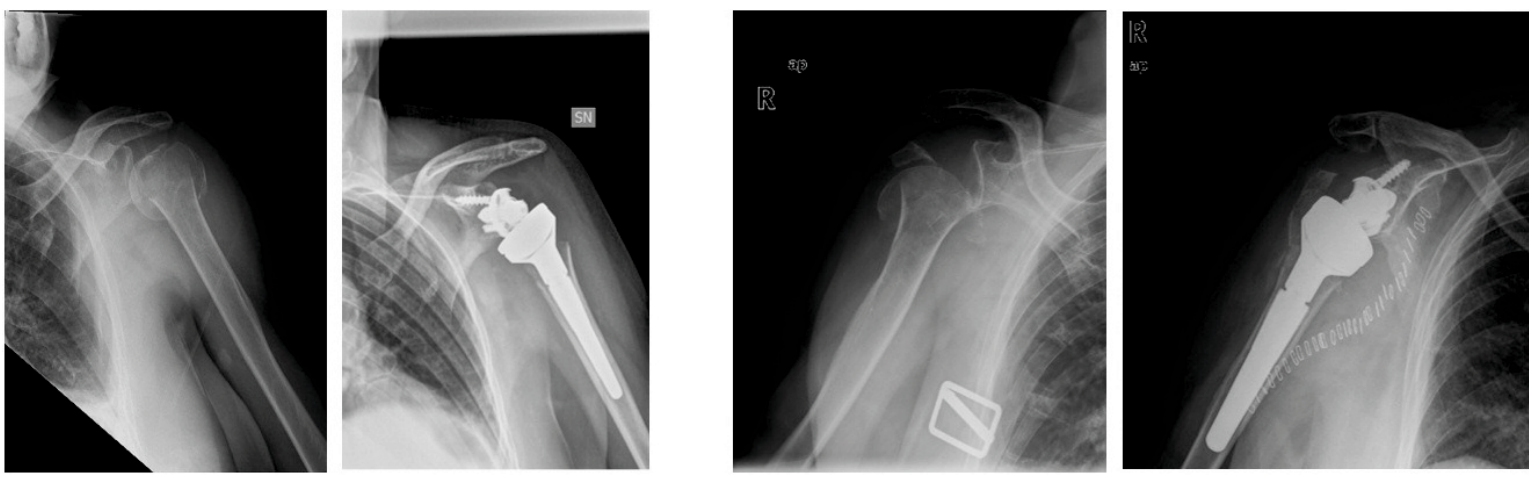

Figure 3. Fractures type $\mathrm{C}$ treated with RSA in a left (40 mm glenosphere) and right shoulder (44 mm glenosphere).

grade 1 in 2 asymptomatic shoulders. Glenoid radiolucency: no loosening of glenoid baseplate observed (Fig. 3), but non-progressive radiolucency around superior the superior screw was evaluated in 1 scapu$\mathrm{la}^{20}$. Humeral radiolucency: no loosening of humeral stem, but non-progressive lucent lines present in 1-27 zones in 1 shoulder. Tuberosities: partial lysis of greater tuberosity present in 1 shoulder and in the lesser tuberosity in 1 RSAs. A scapular spur present in 1 shoulder.

No heterotopic ossification in any case analyzed.

Radiological complications do not seem to have influence on active ROM and Constant Score, both the first and the second group of patients.

\section{Discussion}

Several complications and impaired shoulder function are reported after different types of surgical treatment: the early reports of treatment with ORIF using angular stable plates were promising ${ }^{10,18}$, but later the surgical management of severely displaced fractures and several problems and pitfalls stayed unsolved, as well as complications like cut-out of screws into the joint space, avascular humeral head necrosis, tuberosities reabsorption, loss of fixation, non-union and varus malalignment $^{19}, 20$, a unique set of complications ${ }^{21}$. Some of these complications are caused by poor surgical technique and may be avoidable 22 .

Head replacement or shoulder hemi- or total arthroplasty has been used as a treatment option for three decades and has been claimed a better option than open reduction and fracture fixation in certain severely displaced and dislocated intracapsular fractures, even though the evidence is still not conclusive.

Some related important problems are well known: poor rotator cuff status and non-union of the tuber- 
Table II. Main references in treatment of proximal humerus fractures in old patients with RSA and ORIF.

\begin{tabular}{|c|c|c|c|c|}
\hline Ref. nr & $\begin{array}{c}\text { Number of patients } \\
\text { treated }\end{array}$ & $\begin{array}{l}\text { Surgical } \\
\text { treatment }\end{array}$ & Method of evaluation & Main Features \\
\hline 13 & $\begin{array}{c}28 \text { elderly patients } \\
\text { treated between } 2003- \\
2009\end{array}$ & RSA & $\begin{array}{l}\text { Survivorship and } \\
\text { radiological exams }\end{array}$ & $\begin{array}{l}\text { Good and clinical results at an } \\
\text { average FU of } 54.9 \text { months }\end{array}$ \\
\hline 32 & $\begin{array}{l}51 \text { patients with a mean } \\
\text { age of } 77 \text { years }\end{array}$ & $\begin{array}{l}\text { RSA for acute } \\
\text { fractures }\end{array}$ & $\begin{array}{l}\text { Clinically and } \\
\text { radiologically analyzed }\end{array}$ & $\begin{array}{c}\text { Midterm results are predictably } \\
\text { good with low complication } \\
\text { rates after a mean FU of } 35 \\
\text { months }\end{array}$ \\
\hline 33 & $\begin{array}{c}150 \text { proximal humeral } \\
\text { fractures were treated } \\
\text { operatively }\end{array}$ & $\begin{array}{l}\text { HA, RSA and } \\
\text { ORIF }\end{array}$ & $\begin{array}{l}\text { Total use, annual } \\
\text { utilization rates, age, and } \\
\text { gender were investigated }\end{array}$ & $\begin{array}{l}\text { Utilization rates of ORIF } \\
\text { remained fairly constant. HA } \\
\text { remains the most commonly } \\
\text { used. Increase of RSA }\end{array}$ \\
\hline 34 & $\begin{array}{l}40 \text { patients treated } \\
\text { between } 1996-2004\end{array}$ & $\begin{array}{l}21 \text { pts treated with } \\
\text { HA and } 19 \text { pts } \\
\text { treated with RSA }\end{array}$ & $\begin{array}{l}\text { CS/DASH score and } \mathrm{X}- \\
\text { ray exams }\end{array}$ & $\begin{array}{l}\text { RSA provide reliable, rapid and } \\
\text { predictable results in terms of } \\
\text { ABD, FA and pain relief. RSA } \\
\text { seem indicated on condition } \\
\text { that the patient is no younger } \\
\text { than } 70 \text { yrs }\end{array}$ \\
\hline 44 & $\begin{array}{l}\text { Randomized semi- } \\
\text { blinded controlled } \\
\text { multicenter trial } \\
\text { designed. Participants } \\
\text { are aged } 65-85 \text { admitted } \\
\text { in seven different } \\
\text { hospitals }\end{array}$ & $\begin{array}{l}\text { RSA and angle } \\
\text { stable plates }\end{array}$ & $\begin{array}{l}\text { Oxford shoulder score, } \\
\text { 15D score, semi-blinded } \\
\text { with blinded } \\
\text { physiotherapists } \\
\text { performing }\end{array}$ & NO already results \\
\hline 45 & $\begin{array}{l}92 \text { geriatric patients } \\
\text { treated between } 2000- \\
2004\end{array}$ & angle stable plates & $\begin{array}{l}\text { CS and radiological } \\
\text { exams }\end{array}$ & $\begin{array}{l}\text { Angle stabilising plates did not } \\
\text { lead to a significant } \\
\text { improvement functional } \\
\text { outcome compared with other } \\
\text { ostheosynthesis procedures }\end{array}$ \\
\hline
\end{tabular}

cles. If these main problems are avoided, patients may have a good outcome with these implants ${ }^{23}$. In the elderly patients suffering a proximal humeral fracture, however, the status of the rotator cuff frequently is poor $24-26$; several other Authors also report unsatisfactory results with hemi-arthroplasty ${ }^{27}$ : loss of ROM, non-union of tubercles in as many as $50 \%$ of the patients in some series and above all poor quality of the rotator cuff in functional outcome $27,28$.

Moreover, it's proven that cuff tear and degeneration has a prevalence of almost $20 \%$ in a over 60 years old asymptomatic shoulders population ${ }^{29,30}$, reaching $31 \%$ of patients aged from 70 to 79 years old and $51 \%$ of patients more than 80 years old. Obviously, a complex humeral fracture can upset the balance showed by these shoulders.

During the last decennium the use of RSAs has increased, both as a salvage procedure after failed hemi-arthroplasty but also in the primary fracture care. RSA has gained popularity and has showed promis- ing results in the treatment for proximal humeral fractures in the elderly patients ${ }^{14,31,32}$. A recent large database analysis of 32.150 shoulders underlined the growing importance of RSA in treating proximal humeral fractures in elderly, stating that from 2009 to 2012 the utilization rate of RSA nearly tripled for patients over 65 years old, passing from $11 \%$ to $29 \%$ of treatment choices, to the disadvantage of $\mathrm{HA}$ and a steady trend of ORIF 33 .

There are some evidence in literature that shows better functional outcomes compared to hemi-arthroplasty ${ }^{34}$.

The objectives of this study were to compare two therapeutic methods commonly used to treat old patients with displaced proximal humeral fractures, ORIF and RSA: we noted a significant difference in quality of life of patients treated by reverse shoulder replacement compared with the other group, considering both the Constant score 52.85 for ORIF group versus 64.9 for RSA group $(52.9 \pm 17.0$ vs $65.9 \pm$ $14.7, \mathrm{p}<0.05)$ and Forward flexion and External rota- 
tion $2(p<0.05)$. Our clinical results are comparable or better than other Authors' literature, as summarized in Table II. One of causes of the excellent forward flexion and external rotation in activity daily living activities probably resides in the use of a $44 \mathrm{~mm}$ diameter glenosphere in RSA group, as stated by a recent biomechanical study 35 .

All patients have been reviewed radiologically with $x$ ray images. Our study found better clinical outcomes and fewer complications respectively of most other Authors' works.

The advantage of the concept is less dependence on a normal rotator cuff, as the elderly population frequently suffer asymptomatic degenerative cuff tears leading to a poor prognosis 36,37 . Tearing of the rotator cuff is a recognized complication after TSA ${ }^{38}$ : a secondary rotator cuff dysfunction rate of $17 \%$ following TSA was reported and significantly poorer clinical outcomes were found in these patients compared to those without rotator cuff dysfunction ${ }^{39}$ with a frequent secondary upper migration of the humeral head after anatomic $\mathrm{TSA}^{40}$. In order to avoid the need for a conversion, a reverse prosthesis could be suggested in patients at higher risk, such as the elderly, where the incidence of cuff tears is higher.

Even so, recent findings in over 70 and 80 years old population suggest that age itself should not be considered a reason to implant a reverse instead of an anatomic TSA ${ }^{41}$ or thus to us ORIF in fractures, but the preoperative cuff fatty infiltration grade is primary, in addition to clinical shoulder history.

Recently improved prosthetic designs and improved technique have reduced the problem of notching, due to overhang of the scapular component, instability and poor rotation ${ }^{42}$. RSA works only with a functional deltoid, axillary nerve and adequate bone stock to achieve satisfactory clinical results, thereby forgoing some of the variables necessary for the success with other treatments.

External rotation is not predictably restored following $\mathrm{RSA}^{34,43}$. In some cases, the integrity of some external tendons, teres minor and part of infraspinatus, imply best functional results with a greater degree of external rotation ${ }^{35}, 44$. Finally, it has been suggested that recovery from reverse replacement may be faster than from an anatomic arthroplasty.

The study is not free of limitations in respect of 3 main reasons, with the related selection of bias errors: 1) its retrospective nature, although patients were a consecutive series; 2 ) the sample size, that was small (21 vs 23 shoulders); 3 ) some patients lost to follow-up. We compared two populations that have potentially different surgical indications. Anyway, we did not find any paper in literature that compares clinical results of RSA versus ORIF in these complex proximal humeral fractures, but a designed protocol for a randomized controlled trial that has not arrived yet to final follow-up clinical outcomes ${ }^{45}$.

\section{Conclusion}

The study shows good clinical outcomes and fewer complications in both treatment options. Significant better clinical and daily living results are reported in RSA compared with ORIF, confirming that rTSA is one of the best treatment in proximal humeral fractures in the elderly patients, which rotator cuff status frequently is poor and degenerating. The increasing trend in the use of reverse prosthesis ensures an indication more and more safe in clinical and functional terms with less post-operative complications. The few radiological complications do not seem to have influence on active ROM and Constant Score, for both groups of patients.

Prospective studies with larger case series and with a longer follow-up are needed to further confirm the effectiveness in the use of reverse prosthesis for complex fractures of the proximal humerus.

\section{Conflict of interest}

The Authors have no conflict of interest.

\section{References}

1. Court-Brown CM, Garg A, McQueen MM. The epidemiology of proximal humeral fractures. Acta Orthop Scand. 2001;72 (4):365-371.

2. Neer CS. Displaced proximal humeral fractures. I. Classification and evaluations. J Bone Joint Surg Am. 1970;52(6):10771089.

3. Palvanen MP, Kannus J, Parkkari T, Pitkäjarvi M, Pasanen I, Vuori I, Järvinen M. The injury mechanisms of osteoporotic upper extremity fractures among older adults: a controlled study of 287 consecutive patients and their 108 controls. Osteoporosis Int. 2000;11:822-831.

4. Giannoudis P, Tzioupis C, Almalki T. Fracture healing in osteoporotic fractures: Is it really different? A basic science perspective. Injury. 2007;38(Supp1):S90-S99.

5. Fink HA, Ensrud KE, Nelson DB, Kerani RP, Schreiner PJ, Zhao Y, Cummings SR, Nevitt MC. Disability after clinical fracture in postmenopausal women with low bone density: the fracture intervention trial (FIT). Osteoporos Int. 2003;14:69-76.

6. Hodgson S. Proximal humerus fracture rehabilitation. Clin Orthop Relat Res. 2006;442:131-138.

7. Bell JE, Leung BC, Spratt KF, Koval KJ, Weinstein JD, Goodman DC, Tosteson AN. Trends and variation in incidence, surgical treatment, and repeat surgery of proximal humeral fractures in the elderly. J Bone Joint Surg Am. 2011;93(2):121131.

8. Handoll HHG, Ollivere BJ. Interventions for Treating Proximal Humeral Fractures in Adults. In Cochrane Database of Systematic Reviews. UK: John Wiley \& Sons Ltd. 2010;12.

9. Nho SJ, Brophy RH, Barker JU, Cornell CN, MacGillivray JD. Management of proximal humeral fractures based on current litterature. J Bone Joint Surg Am. 2007;89:44-58.

10. Solberg BD, Moon CN, Franco DP, Paiement GD. Surgical treatment of three and four-part proximal humeral fractures. J Bone Joint Surg Am. 2009;91(7):1689-1697. 
11. Robinson CM, Page RS, Hill RMF, Sanders DL, Court-Brown $\mathrm{CM}$, Wakefield AE. Primary hemiartroplasty for treatment of proximal humeral fractures. J Bone Joint Surg Am. 2003;85: 1215-1223.

12. Reitman RD, Kerzhner E. Reverse shoulder arthoplasty as treatment forcomminuted proximal humeral fractures in elderly patients. Am J Orthop (Belle Mead NJ). 2011;40(9):458-461.

13. Ross M, Hope B, Stokes A, Peters SE, McLeod I, Duke PF. Reverse shoulder arthroplasty for the treatment of three-part and four-part proximal humeral fractures in the elderly. $J$ Shoulder Elbow Surg. 2015 Feb;24(2):215-222.

14. Mata-Fink A, Meinke M, Jones C, Kim B, Bell JE. Reverse shoulder arthroplasty for treatment of proximal humeral fractures in older adults: a systematic review. J Shoulder Elbow Surg. 2013 Dec;22(12):1737-1748.

15. Sadoghi P, Leithner A, Vavken P, Hölzer A, Hochreiter J, Weber G, Pietschmann MF, Müller PE. Infraglenoidal scapular notching in reverse total shoulder replacement: a prospective series of 60 cases and systematic review of the literature. BMC Musculoskelet Disord. 2011;12:101. doi:10.1186/1471-247412-101.

16. Levigne C, Boileau P, Favard L, Garaud P, Mole D, Sirveaux $F$, Walch $G$. Scapular notching in reverse shoulder arthroplasty. J Shoulder Elbow Surg. 2008;17(6):925-935.

17. Rice RS, Sperling JW, Miletti J, et al. Augmented glenoid component for bone deficiency in shoulder arthroplasty. Clin Orthop Relat Res. 2008 Mar;466(3):579-583.

18. Sommer C, Gautier E, Müller M, Helfet DL, Wagner M. First clinical results of the Locking Compression Plate (LCP). Injury. 2003;34:43-54.

19. Hertel R. Fractures of the proximal humerus in osteoporotic bone. Osteoporos Int. 2005;16(Suppl 2):S65-S72.

20. Agudelo J, Schürmann M, Stahel P, Helwig P, Morgan SJ, Zechel W, Bahrs C, Parekh A, Ziran B, Williamns A, Smith W. Analysis of efficacy and failure in proximal humerus fractures treated with locking plates. JOrthop Trauma. 2007;21(10):676681.

21. Solberg BD, Moon CN, Franco DP, Paiement GD. Locked plating of three and four-part proximal humeral fractures in older patients: the effect of initial fracture pattern on outcome. J Orth Trauma. 2009;23:113-119.

22. Robinson CM, Amin AK, Godley KC, Murray IR, White TO. Modern perspectives of open reduction and plate fixation of proximal humerusfractures. J Orthop Trauma. 2011;25(10): 618-629.

23. Boileau P, Krishnan SG, Tinsi L, Walch G, Coste JS, Molé D. Tuberosity malposition and migration: reasons for poor outcomes after hemiarthroplasty for displaced fractures of the proximal humerus. J Shoulder Elbow Surg. 2002;11(5):401412.

24. Bahrs C, Rolauffs B, Stuby F, Dietz K, Weise K, Helwig P. Effect of proximal humeral fractures on the age-specific prevalence of rotator cuff tears. J Trauma. 2010;69(4):901-906.

25. Via AG, De Cupis M, Spoliti M, Oliva F. Clinical and biological aspects of rotator cuff tears. Muscles Ligaments Tendons $\mathrm{J}$. $2013 \mathrm{Jul} ; 9 ; 3(2): 70-79$.

26. Gallo RA, Sciulli R, Daffner RH, Altman DT. Defining the relationship between rotator cuff injury and proximal humerus fractures. Clin Orthop Relat Res. 2007;458:70-77.

27. Kralinger F, Schwaiger R, Wambacher M, Farell E, MenthChiari W, Lajtai G, Hübner C, Resch H. Outcome after primary hemiarthroplasty for fracture of the head of the humerus. J Bone Joint Surg (Br). 2004;86(2):217-219.

28. Becker R, Pap G, Machner A, Neumann WH. Strength and motion after hemiarthroplasty in displaced four-fragment frac- ture of the proximal humerus: 27 patients followed for 1-6 years. Acta Orthop Scand. 2002;73(1):44-49.

29. Oliva F, Maffulli N, et al. I.S.Mu.L.T. Rotator Cuff Tears Guidelines. Muscles Ligaments Tendons J. 2016 Feb;13;5(4):227263.

30. Temelhof S, Rupp S, Seil R. Age-related prevalence of rotator cuff tears in asymptomatic shoulders. J Shoulder Elbow Surg. 1999 Jul-Aug;8(4):296-299.

31. Garrigues GE, Johnston PS, Pepe MD, Tucker BS, Ramsey ML, Austin LS. Hemiartroplasty versus reverse total shoulder arthroplasty for acute proximal humeral fractures in elderly patients. Orthopedics. 2012;35(5):e703-e708.

32. Grubhofer F, Wieser K, Meyer DC, Catanzaro S, Beeler S, Riede U, Gerber C. Reverse total shoulder arthroplasty for acute head-splitting, 3- and 4-part fractures of the proximal humerus in the elderly. J Shoulder Elbow Surg. 2016 Oct.

33. Rosas S, Law TY, Kurowicki J, Formaini N, Kalandiak SP, Levy JCJ. Trends in surgical management of proximal humeral fractures in the Medicare population: a nationwide study of records from 2009 to 2012. Shoulder Elbow Surg. 2016 Apr;25(4):608-613.

34. Gallinet $D$, Clappaz $P$, Garbuio $P$, Tropet $Y$, Obert $L$. Three or four parts complex proximal humerus fractures: hemiarthroplasty versus reverse prosthesis: a comparative study of 40 cases. Orthop Traumatol Surg Res. 2009 Feb;95(1):48-55.

35. Berhouet J, Garaud P, Favard L. Influence of glenoid component design and humeral component retroversion on internal and external rotation in reverse shoulder arthroplasty: A cadaver study Orthopaedics \& Traumatology: Surgery \& Research. 2013:99:887-894.

36. Moosmeyer S, Smith HJ, Tariq R, Larmo A. Prevalence and characteristics of asymptomatic tears of the rotator cuff: an ultrasonographic and clinical study. J Bone Joint Surg (Br). 2009;91(2):196-200.

37. Chin $P Y$, Sperling JW, Cofield RH, Schleck C. Complications of total shoulder arthroplasty: are they fewer or different? J Shoulder Elbow Surg. 2006;15:19-22.

38. Young A A, Walch G, Pape G, Gohlke F, Favard L. Secondary rotator cuff dysfunction following total shoulder arthroplasty for primary glenohumeral osteoarthritis: Results of a multicenter study with more than five years of follow-up. J Bone Joint Surg (Am). 2012;94(8):685-693.

39. Foruria A M, Sperling J W, Ankem HJ, Oh L S, Cofield R H. Total shoulder replacement for osteoarthritis in patients 80 years of age and older. J Bone Joint Surg (Br). 2010;92(7):970-974.

40. Iriberri I, Candrian C, Freehill MT, Raiss P, Boileau P, Walch G. Anatomic shoulder replacement for primary osteoarthritis in patients over 80 years: outcome is as good as in younger patients. Acta Orthop. 2015 Jun;86(3):298-302. doi: 10.3109/ 17453674.2015.1006036. Epub 2015 Jan 14.

41. De Wilde LF, Poncet D, Middermacht B, Ekelund A. Prosthetic overhang is the most effective way to prevent scapular conflict in a reverse total shoulder prosthesis. Acta Orthop. 2010;81(6):719-726.

42. Cazeneuve JF, Cristofari DJ. Grammont reversed prosthesis for acute complex fracture of the proximal humerus in an elderly population with 5 to 12 years follow-up. Orthop Traumatol Surg Res. 2014 Feb;100(1):93-97.

43. Ackland DC1, Richardson M, Pandy MG. Axial rotation moment arms of the shoulder musculature after reverse total shoulder arthroplasty. J Bone Joint Surg Am. 2012 Oct;17;94 (20):1886-1895. doi: 10.2106/JBJS.J.01861.

44. Fjalestad Tore, Petter Iversen, Margrethe Øye Hole. Morten Smedsrud and Jan Erik Madsen Clinical investigation for dis- 
placed proximal humeral fractures in the elderly: a randomized study of two surgical treatments: reverse total prosthetic replacement versus angular stable plate Philos (The DELPHI trial) BMC Musculoskeletal Disorders. 2014;15:323.

45. Frangen TM, Müller EJ, Dudda M, Arens S, Muhr G, Kälicke T. Proximal humeral fractures in geriatric patients. Is the angle- sable plate osteosynthesis really a breakthrough? Acta Orthop Bel. 2007;73(5):571-579.

46. Padulo J, Oliva F, Frizziero A, Maffulli N. Muscles, Ligaments and Tendons Journal - Basic principles and recommendations in clinical and field science research: 2016 update. MLTJ. 2016;6(1):1-5. 